\title{
Design and Simulation of Very Low Head Axial Hydraulic Turbine with Variation of Swirl Velocity Criterion
}

\author{
Abdul Muis ${ }^{1,2}$, PriyonoSutikno ${ }^{1}$ \\ ${ }^{1}$ Faculty of Mechanical and Aerospace Engineering, Bandung Institute of Technology \\ Jalan Ganesha 10, Bandung, 40132, Indonesia, \\ ${ }^{2}$ Department of Mechanical Engineering, Tadulako University \\ Jalan Soekarno-Hatta, Palu, 94224, Indonesia
}

\begin{abstract}
The type of turbine developed is based on the very low head of water potential source for the electric power production. The area of research is focused for the axial water turbine that can be applied at the simple site open channel with has a very low cost and environmental impact compared to the conventional hydro installation. High efficiency of axial turbine which applied to the very low potential head will made this type of turbine can be used at wider potential site. Existing irrigation weir and river area will be the perfect site for this turbine.

This paper will compare the effects of the variation of swirl velocity criterion during the design of the blade of guide vane and rotor of the turbine. Effects of the swirl velocity criterion is wider known as a vortex conditions (free vortex, force vortex and swirl velocity constant), and the free vortex is the very popular condition that applied by most of turbine designer, therefore will be interesting to do a comparison against other criterion. ANSYS Fluent will be used for simulation and to determine the predictive performance obtained by each of design criteria.
\end{abstract}

Keywords: Axial turbine, very low head turbines, swirl velocity, vortex, ANSYS Fluent.

\section{Introduction}

Hydro is the largest producer of renewable energy in the world, with a total global capacity of 1067 GW in 2011[1]. Especially in Indonesia, from the data published by the Energy and Mineral Resources of Indonesia in 2012, the hydro energy potential available in Indonesia at this time was $75 \mathrm{GW}$ for large-scale (10 MW per site) with total installed capacity of $4.2 \mathrm{GW}$, and 450 MW for small scale (less than $10 \mathrm{MW}$ per site) with the use of $84 \mathrm{MW}$ [2]. This indicates that the utilization of this energy source is still very low in Indonesia. Various obstacles are caused such a large investment, environmental impact, geographical aspects which the potential sources are far away from the users and etc.

The very low head turbine type that became as a topic of this research is the axial flow turbine which its installation is highly suited to flow with considerable discharge because the power is generated predominantly influenced by the amount of water passing through the turbine capacity because the useful head is very low. The installation is quite simple, because it does not require the complex construction of canal to regulate the flow at the inlet and outlet of the turbine. Hydro turbine for power generation application on really low head potential source has a number of advantages such as low environmental impact, lower investment in construction location of the potential sites are relatively close to the consumer and also will be easily in installation because of its can be as a compact turbine. Thus the turbine type can be a solution in the utilization of the hydro energy potential in Indonesia and around the world.

In this study will be found out the influence of swirl velocity that occurs in fixed blade turbine and its influence on the overall efficiency of the turbine work. The existence of the swirl velocity caused by the blade row and these blades will disrupt the meridional flow of turbine from hub to shroud. In the conventional design method of two-dimensional (2D), the influence of swirl velocity is often ignored by assuming that the meridional flow before and after the blade row remains constant from hub to shroud and is considered the same as the meridional flow that occurs in the middle of the blade radius, and this method is also known as a

Received February 24 2014; accepted for publication March 20 2014: Paper number O14012S

Corresponding author: Priyono Sutikno, Professor, priyonosutikno@yahoo.com

This paper was presented at 12th Asian International Conference on Fluid Machinery (AICFM), September 25-27 2013, Jogyakarta, Indonesia 
free vortex design analysis. Otherwise, in reality, the flow conditions that occur from hub to shroud of turbine blades will vary and the blade shape itself are usually tapered and twisted from the hub to the casing. Turbine design analysis involving the influence of swirl velocity on the blade and combine it with conventional 2D design analysis is also known as quasi three-dimensional (Q3D) design analysis.

\section{Meridional Flow and Swirl Velocity}

\subsection{Meridional Flow}

For axial turbomachine, hub and casing are cylindrical, so is very reasonable to assume that the surface stream that goes up through to the turbine exit will remain cylindrical. The stream surface from hub to shroud formed meridional flow $\epsilon_{x}$, fig. 1 (left). Downstream of the blade row, however the swirling flows are quite considerably, resulting in the pressure gradient. This can result in a shifted of radial meridional flow lines, fig. 1 (right), and the meridional flow $c_{x}$ will varies from hub to shroud.
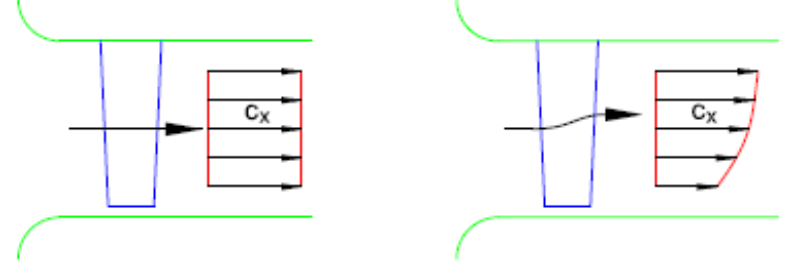

Fig. 1 Meridional flow through an axial turbomachine

The main thing affects the meridional flow after passing through the blade row is the existence of swirl velocity $c_{g}$ at the blade row. There are three types of swirl velocity which will be discussed in this paper, they will affect the meridional flow and will give a different effect on the fluid velocity triangles that occur in turbine blades. All of those criterions are free vortex, forced vortex and $c_{\theta}$ constant.

\subsection{Free Vortex Swirl Velocity}

If we re-observe the flow produced by the vortex, as illustrated by fig. 2, where the flow field in the $z$, $y$ plane which is forced by the line vortex of strength $\Gamma$, which works along the $x$ axis, the vortex velocity is:

$$
\sigma_{\theta}=\frac{F}{\sin r}
$$

This vortex type is also known as the free vortex condition

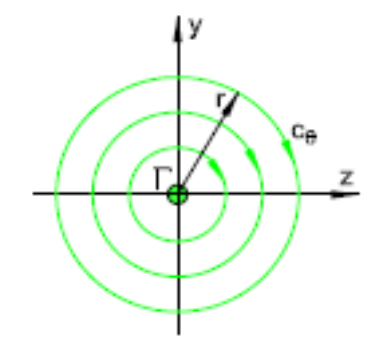

Fig. 2 Flow field by vortex of strength $\Gamma$ lying along the $x$-axis

On axial flow turbomachinery with incompressible fluid, at radius $r$, the Euler pump equation with zero pre-whirl upstream of the blade, may be expressed in the equation [3]:

$$
W=\frac{1}{\rho} \Delta p_{b E}=U c_{g 2}=r \Omega c_{g 2}
$$

Where $\bar{W}$ is the specific work input and $\Delta_{F \in E}$ is the stagnation pressure rise, if a constant specific work input for all radii are adopted, equation condition at the mean radius $r_{\mathrm{m}}$ to any other radius $r$ obtain

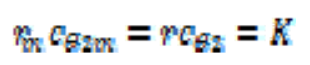

Or can be expressed as:

$$
\epsilon_{g}=K \xi r
$$

where $\varepsilon_{g}$ is the swirl velocity, $\mathbb{K}$ is the constant and $r$ is radius of blade. This equation is similar with free vortex condition as 
mentioned above where the swirl velocity is inversely proportional to radius. Thus, if we are using $c_{\theta}$ criterionthat obtained in equation 3 in the analysis of the meridional flow turbine, the vortex free criteria have been applied in determining the meridional flow at the velocity triangle of turbine.

\subsection{Non-Free Vortex Swirl Velocity}

The swirl velocity for forced vortex criterion can be expressed as follows:

$$
\vartheta=K, r
$$

And for the swirl velocity constant:

$$
\epsilon_{g}=K
$$

\section{Radial Equilibrium Analysis}

One of the simple approaches that can be used to analyze the meridional flow that occurs inside the axial turbine is radial equilibrium analysis. Figure 3(left) illustrates the meridional flow that shifted radials inward progressively under the influence of the radial pressure gradient $d p k d r$ caused by the swirling flow down-stream of the blade row.

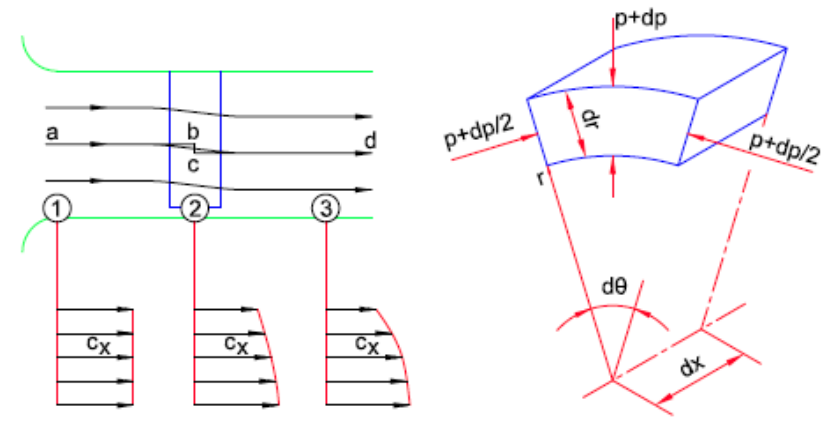

Fig. 3 Radial equilibrium of a fluid element downstream of the blade row

Furthermore, there will be a steady growth in the slope of the axial velocity profile $\sigma_{X}$. At a certain distance from the downstream blade row at position 3, the radial velocity component $\boldsymbol{c}_{\gamma}$ approaches zero, resulting flow condition which known as radial equilibrium. Radial momentum balance is then be achieved between the radial pressure gradient dp/drand the angular momentum of the fluid $r c_{g}$. This method has been developed by Lewis [3], which is used in the analysis of the meridional flow on the fan, and will result the equation as shown in the fig. 3 that describes the relationship of the radial momentum balance refers to the equilibrium of a small element of fluid at radius $r$, by adopting cylindrical polar coordinates $x, r$, $\theta$, where the $x$ axis is the axis of turbine rotation. The equation to describe relationship between the radials inward pressure forces on the face of the element to its centrifugal acceleration is:

$$
\frac{1 d p}{\rho r}=\frac{g}{r}
$$

For free vortex flow condition, with $r c_{g}$ are constant and $\varsigma_{\S}=\frac{\Gamma}{2 \pi}$ the equation above can be expressed as:

$$
\frac{1}{p d x}=\frac{r^{2}}{4 \pi^{2} r^{2}}
$$

where for free vortex conditions $\varepsilon_{x}$ is constant.

For non-free vortex flow where $r c_{g}$ is not constant, it is necessary to know relationship between the axial velocity $c_{x}$ against $\epsilon_{g}$ and $p$. For incompressible flow conditions for which we may define the stagnation pressure $p_{0}$ through:

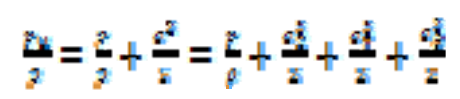

By differentiation of the above equation with respect to $r$ and putting $c_{r}=0$, then

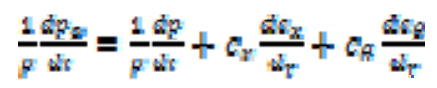

Introducing $d p / d d^{*}$ from equation(6), then the radial equilibrium equation for incompressible flow is:

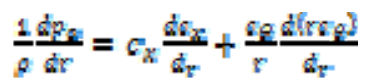


To design guide vane that will be used in this very low head turbine, the equilibrium radial analysis is used to determine the swirl velocity and then control the meridional flow after the guide vane that will affect the velocity triangle that occurs on turbine rotor. By solving the above equation for conditions of forced vortex and swirl $c g=k r$ and swirl velocity constant $c_{g}=\kappa$, will be obtained:

$$
\begin{aligned}
& \frac{\varepsilon_{x}}{\varepsilon_{x}}=\sqrt{1+\left(1+h^{2}-2\left(\frac{r}{r_{r}}\right)^{2}\right)\left(\frac{c_{r}}{c_{x}}\right)^{2}} \quad \text { (forced vortex) } \\
& \frac{\varepsilon_{x}}{\varepsilon_{x}}=\sqrt{1+2\left(\frac{\sigma_{x}}{c_{x}}\right)^{2} \ln \left(\frac{r_{m}}{r}\right)} \quad \text { (swirl velocity constant) }
\end{aligned}
$$

where $C_{x}$ is the mean axial velocity, $c_{x}$ is axial velocity from hub to tip, $h$ is perbandingan radius hub to tip, $r$ is radius, $\eta_{t}$ is the tip radius and $c_{e s}$ is the tip swirl velocity. By applying this equation, the meridional velocity at conditions non-free vortex may be resolved.

\section{Turbine Power}

\subsection{Water Power and Designed Turbine Power}

Powers generated by this turbine type tend to use the capacity of the flow through the annulus and turbine blades. Position of very low head turbine may be described in the following chart which shows the utilization of potential of hydro energy sources compare to other types of water turbines.

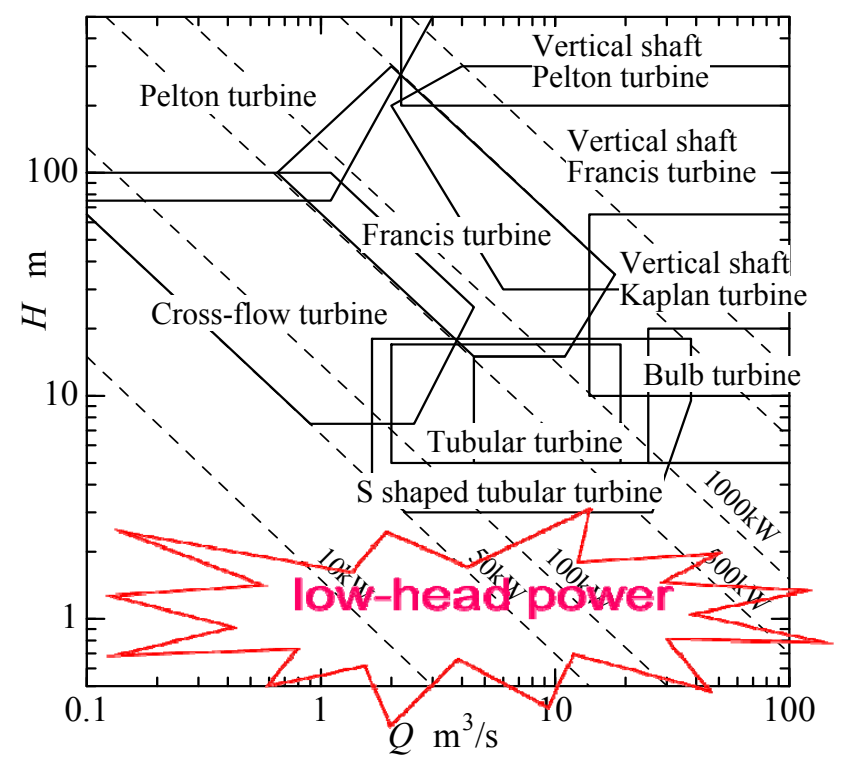

Fig. 4 Selection chart of hydro turbine [4]

The potential energy of water source $\mathbb{P}_{w}$, may be described by the following equation:

$$
F_{W}=\rho Q R
$$

Where pis the water density, $g$ is the acceleration of gravity, $Q$ is the water flow rate and $H$ is the potential head of site. To produce a high power, this type of turbines also requires a high flow rate of water.

To generate the potential energy of hydro power, turbine runner blades are made to be able to absorb and redirects the energy potential to the maximum level (high efficiency). Designing of runner blades on the base of flow conditions is very important to gain the optimum efficiency. For this purpose, the geometry of the rotor blade will adopt an airfoil shape with certain characteristics to gain the maximum efficiency of designed turbine.

There are two main forces of the water acting on the runner blades and greatly affect the efficiency, the lift and drag force. Both can be written mathematically in equation (14) and (15).

$$
\begin{aligned}
& \Delta L=C_{2}, \rho \cdot \frac{v_{R}^{2}}{r} E, d r[\mathrm{~N}] \\
& \Delta D=c_{Q}, \rho \frac{V_{\pi}^{2}}{2} \hbar d r \quad[\mathrm{~N}]
\end{aligned}
$$

The force acting on blade in the rotational direction $F_{u}$

$$
F_{u}=F_{1} \cos \left(\frac{\pi}{a}-\beta_{\mathrm{se}}+\lambda\right)=F_{1} \sin \left(\beta_{\mathrm{se}}-\lambda\right)[\mathrm{N}]
$$




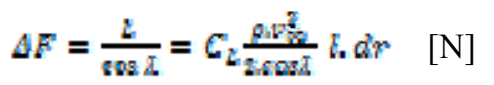

The energy produces by designed turbine $P_{Z}$,

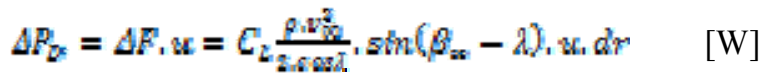

Where $L$ and $D$ is the lift and drag force, $C_{L}$ and $\sigma_{D}$ is the lift and drag coefficient, $\rho$ is the water density, $v_{s}$ is the velocity of water enters the blade, $l$ is the chord length of blade, and $r$ is the blade radius.

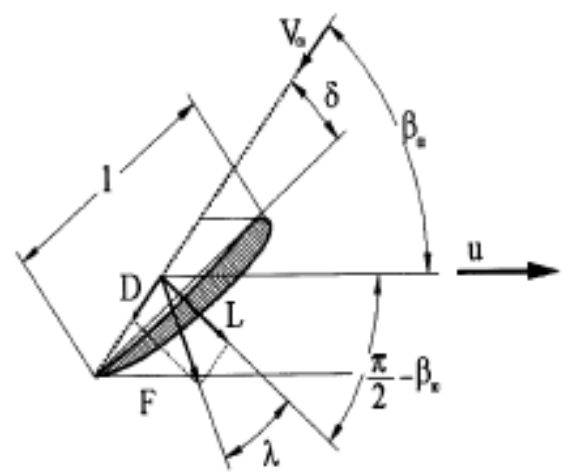

Fig. 5 Vector components of forces acting on a runner blade

Then, the airfoil with a high ratio of lift and drag coefficient with the ability to receive the load force $F$ in the range of designed operating of turbine will be more attractive option for designers.

\subsection{Turbine Power from Simulation Results}

Power generated by the CFD simulations can be written as follows:

$$
P_{\text {twrime }}=T_{\text {tat }}, \omega
$$

The turbine efficiency, $\eta_{T}$ is

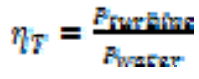

\section{Guide Vane and Rotor Blade Geometry}

Turbines are designed to operate with water discharge $0.55 \mathrm{~m}^{2} / \mathrm{s}(549 \mathrm{~kg} / \mathrm{s})$. From the calculations, the outer diameter of 0.6 meter turbine blade motion and hub 0.2 meters and will work on a $180 \mathrm{rpm}$ with 24 guide vanes and 4 rotor blades. To design guide vane and rotor blade turbine, the condition of swirl velocity which has been discussed previously, free vortex, forced vortex and swirl velocity constant applied. And combination with blade to blade flow analysis, we obtained the guide vane and rotor blade geometry details as shown in table 1 . Each blade is divided into 11 sections, but only 3 sections are shown here, section hub, mid and tip to show the differences between them. NACA0012 airfoil blade is used for guide vanes and Goettingen0480 airfoil for rotor blade.

Table 1Parameters of guide vane and rotor blade geometry

\begin{tabular}{l||c|c|c||c|c|c||c|c|c}
\hline \multicolumn{1}{c||}{ Description } & \multicolumn{3}{c||}{ Free Vortex } & \multicolumn{3}{c||}{ Forced Vortex } & \multicolumn{3}{c}{ Swirl Velocity Constant } \\
\hline Section & Hub & Mean & Tip & Hub & Mean & Tip & Hub & Mean & Tip \\
\hline Swirl velocity, $\boldsymbol{c}_{\boldsymbol{\theta}}(\boldsymbol{m} / \boldsymbol{s})$ & 1.4054 & 0.7027 & 0.4685 & 0.2342 & 0.4685 & 0.7027 & 0.4685 & 0.4685 & 0.4685 \\
\hline Meridional velocity $(m / s)$ & 2.1888 & 2.1888 & 2.1888 & 2.2629 & 2.1888 & 2.0599 & 2.2573 & 2.1888 & 2.1478 \\
\hline
\end{tabular}

Guide Vane

\begin{tabular}{l||c|c|c||c|c|c||c|c|c}
\hline Inlet angle, $\beta_{1}\left(^{\circ}\right)$ & 0 & 0 & 0 & 0 & 0 & 0 & 0 & 0 & 0 \\
\hline Outlet angle, $\beta_{\mathbf{2}}\left(^{\circ}\right)$ & 57.29 & 72.20 & 77.92 & 84.09 & 77.92 & 71.16 & 78.275 & 77.919 & 77.696 \\
\hline Chamber Angle, $\theta\left(^{\circ}\right)$ & 32.70 & 17.80 & 12.08 & 5.91 & 12.08 & 18.84 & 11.725 & 12.081 & 12.304 \\
\hline
\end{tabular}




\begin{tabular}{l||c|c|c||c|c|c||c|c|c}
\hline Tip and chord ratio, $t / l$ & 0.333 & 0.667 & 1 & 0.333 & 0.667 & 1 & 0.333 & 0.667 & 1 \\
\hline Chord length, $l(m)$ & 0.080 & 0.080 & 0.080 & 0.080 & 0.080 & 0.080 & 0.080 & 0.080 & 0.080 \\
\hline Number of blade, $z$ & 24 & 24 & 24 & 24 & 24 & 24 & 24 & 24 & 24 \\
\hline
\end{tabular}

\section{Rotor Blade}

\begin{tabular}{l||c|c|c||c|c|c||c|c|c}
\hline Inlet angle, $\beta_{3}\left({ }^{\circ}\right)$ & 57.29 & 72.20 & 77.92 & 84.09 & 77.92 & 71.16 & 78.27 & 77.92 & 77.70 \\
\hline Blade angle, $\beta_{\odot}-\delta\left(^{\circ}\right)$ & 57.63 & 28.64 & 17.99 & 48.01 & 27.77 & 17.23 & 49.83 & 27.77 & 17.62 \\
\hline Tip and chord ratio, $t / l$ & 0.988 & 0.988 & 0.988 & 0.961 & 0.961 & 0.961 & 0.985 & 0.985 & 0.985 \\
\hline Chord length, $l(m)$ & 0.158 & 0.317 & 0.475 & 0.167 & 0.335 & 0.502 & 0.163 & 0.325 & 0.488 \\
\hline Number of blade, $z$ & 4 & 4 & 4 & 4 & 4 & 4 & 4 & 4 & 4 \\
\hline
\end{tabular}

From the table above, will be generated guide vanes and rotor blade as shown in fig. 6 and 7. Final design of the turbine illustrated on fig. 8 , with $350 \mathrm{~mm}$ length from front face to the end of the turbine outlet. Models were created with Autodesk Inventor Pro 2012.
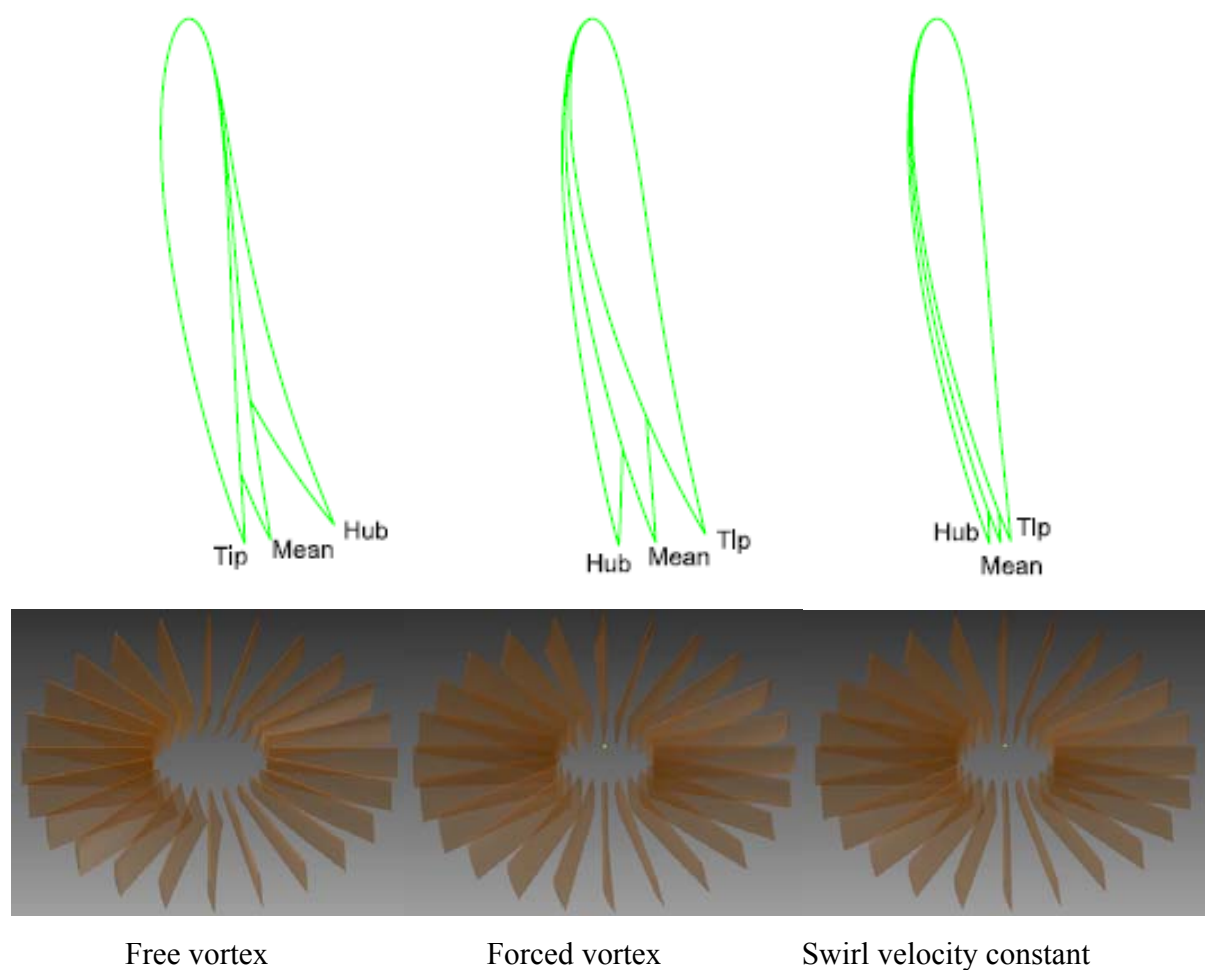

Fig. 6 Comparison of turbine guide vane geometries
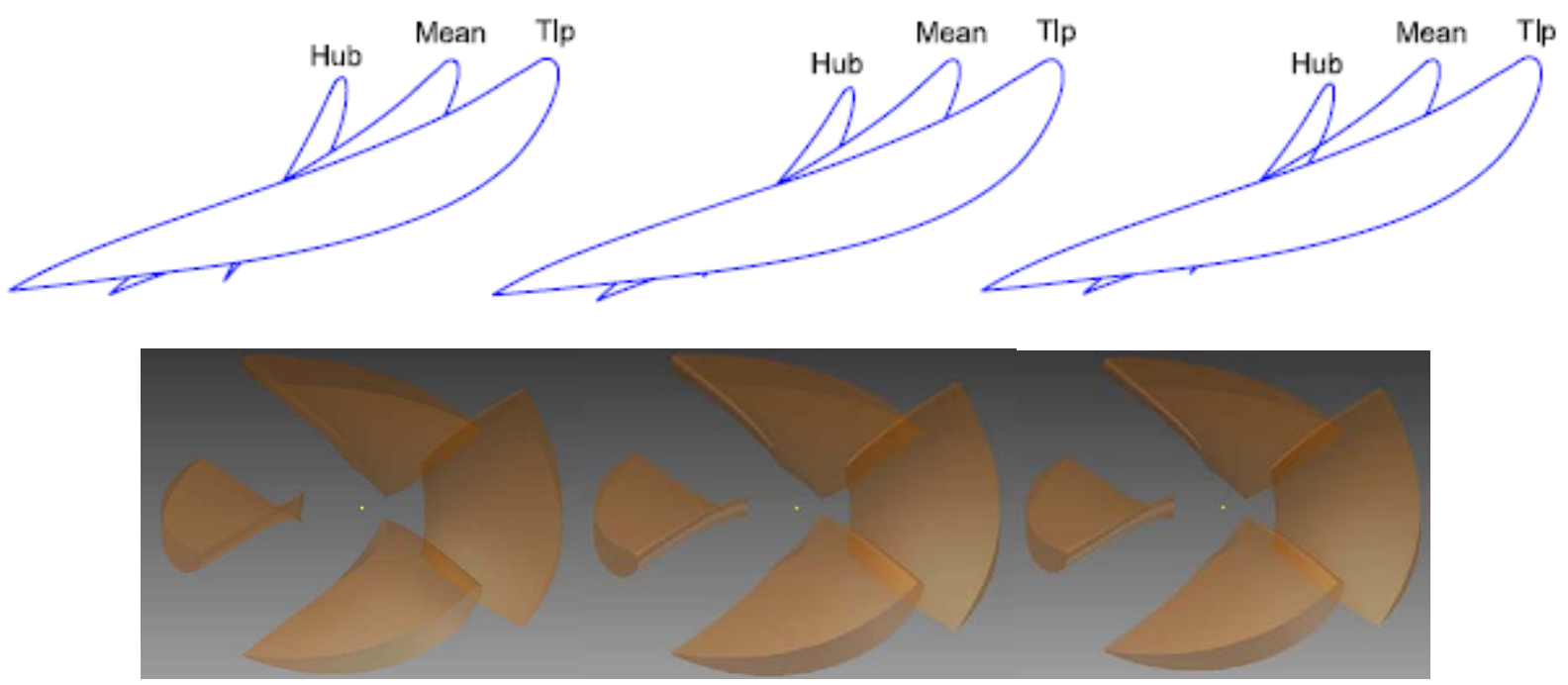

Free vortex Forced vortex

Swirl velocity constant

Fig. 7 Comparison of turbine rotor blade geometries 


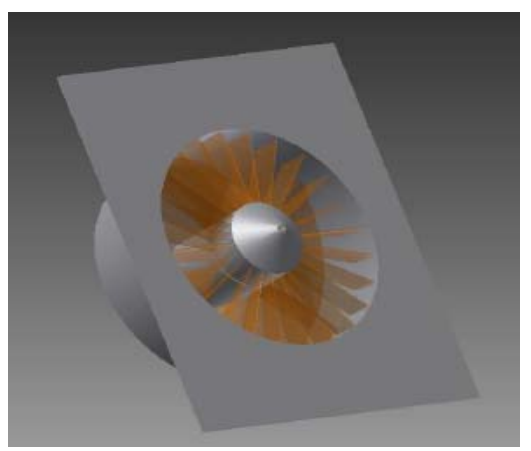

Fig. 8 Final design of very low head turbine

\section{Turbine Installation}

Turbine model obtained is placed in the canal at an angle of 45 degree. The author believes this position will provide an advantage in exploiting the potential energy in the flowing water inside the canal.

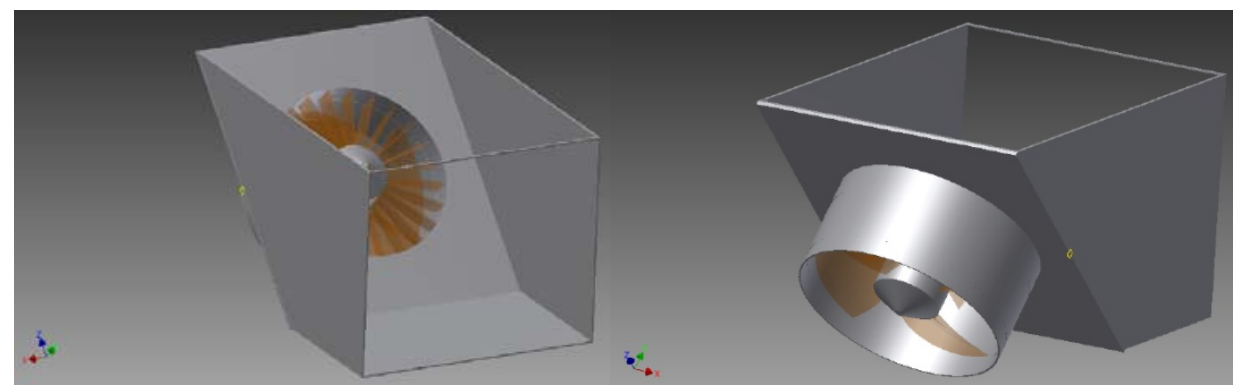

Fig. 9 Turbine installation at 45 degree position

\section{Simulation and Results}

To validate and study the performance of the turbine, CFD simulations are performed using ANSYS Fluent 12.1. The analysis type of 3Dandviscous model k $\omega$-SST models [5]. For set of boundary conditions mass flow rate was specified at the inlet and pressure outlet at was specified at the outlet. Turbine inlet and outlet forming an angle of 90 degrees which is adapted to the conditions of water flow testing at ITB Bandung. Experimental analysis also prepared but it is not part of this paper.

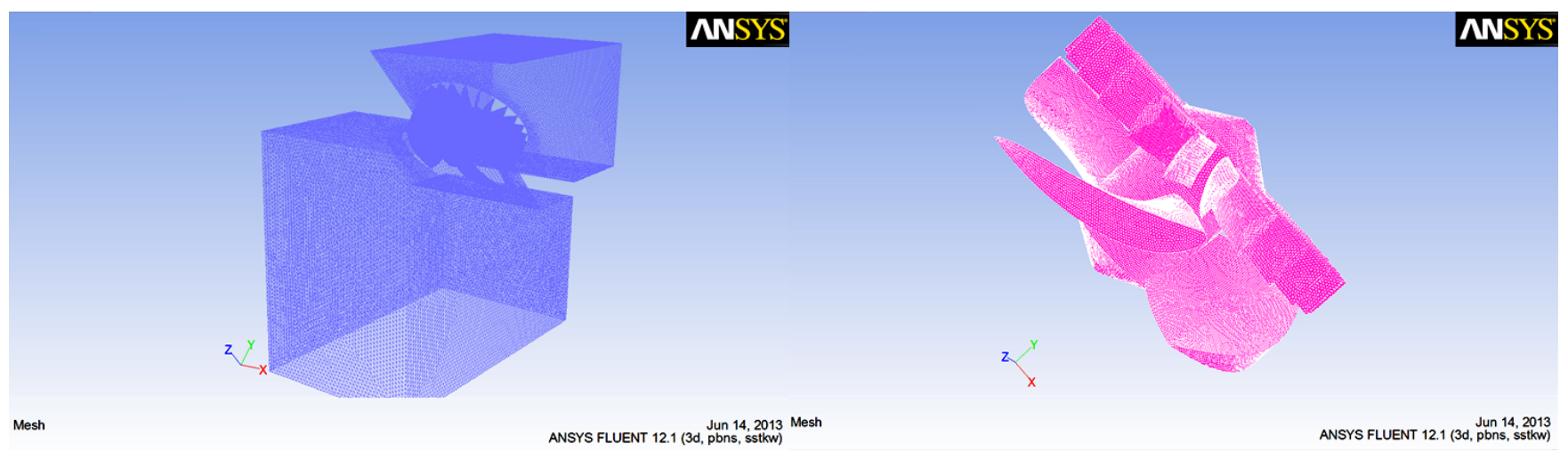

Fig. 10 Meshed model of turbine installation (left) and guide vane \& rotor blade of turbine (right)

\subsection{Free Vortex Result}

The simulation results of free vortex criterion as shown on fig. 11, 12, 13 and 14. For designed range operation, mass flow rate $549 \mathrm{~kg} / \mathrm{s}$ and rotation $180 \mathrm{rpm}$, the maximum efficiency that can be achieved is $89.36 \%$ and the total power generated is 1,986

$\mathrm{kW}$. Results from the three simulations are performed with different mass flow rate indicates that the turbine have a maximum efficiency close to $90 \%$ at different angular velocities. Distribution of velocity and static pressure that occurs on the installation is 
shown on fig. 13. These indicate that the velocity of fluid flow in the area of the blade turbine outlet is higher than others area and the minimum static pressures also are shown on the same area. Static pressures of the turbine blade are shown on fig. 14, where on pressure side looks has higher pressure that suction side. Especially along the leading edge, highest static pressure occurred in this area and the lowest static pressure occurred on suction side of turbine blade in the areas adjacent to the leading edge. Minimum and maximum static pressure that occurs are $-16.947 \mathrm{kPa}$ and $11.940 \mathrm{kPa}$ respectively.

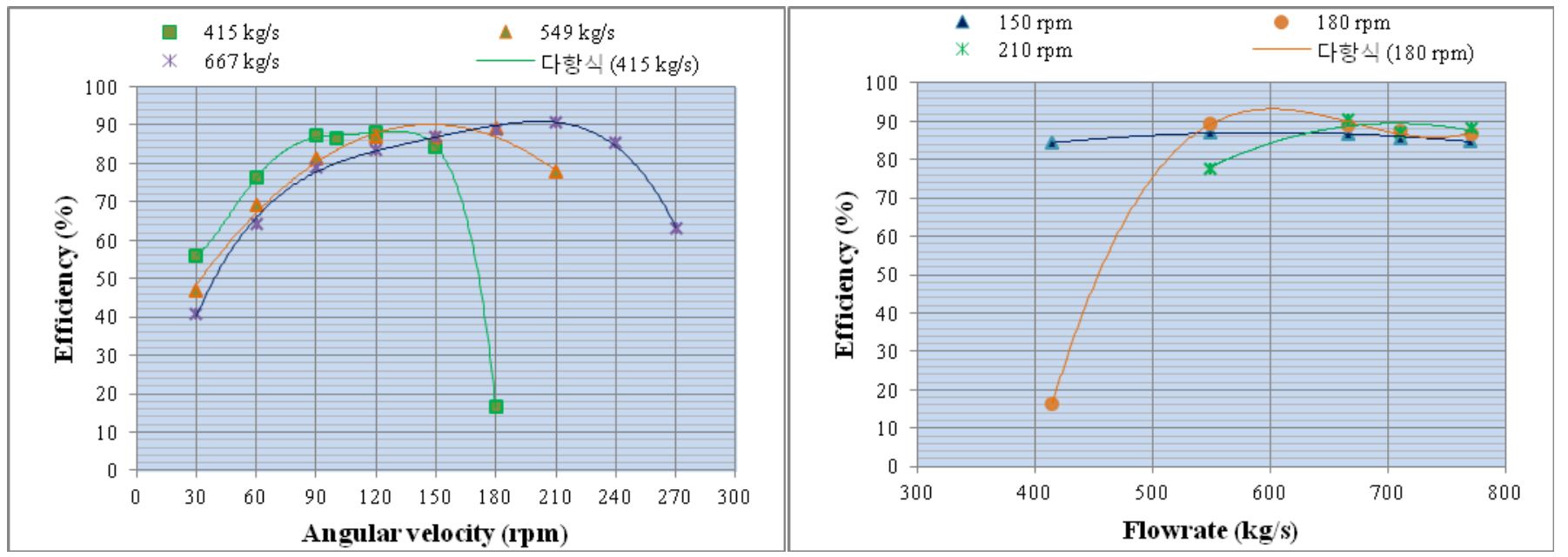

Fig. 11 Efficiency results at various of angular velocity and flow rate

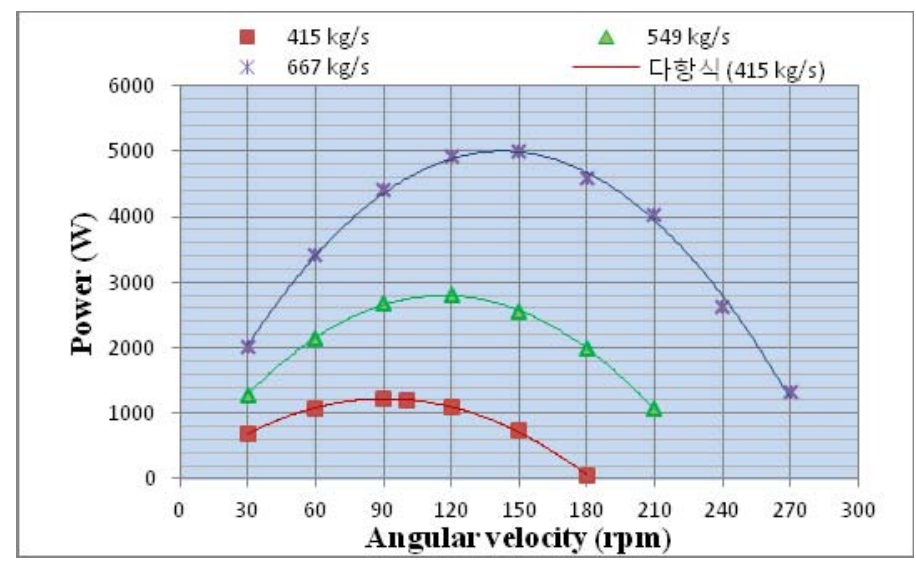

Fig. 12 Power results at various of angular velocity

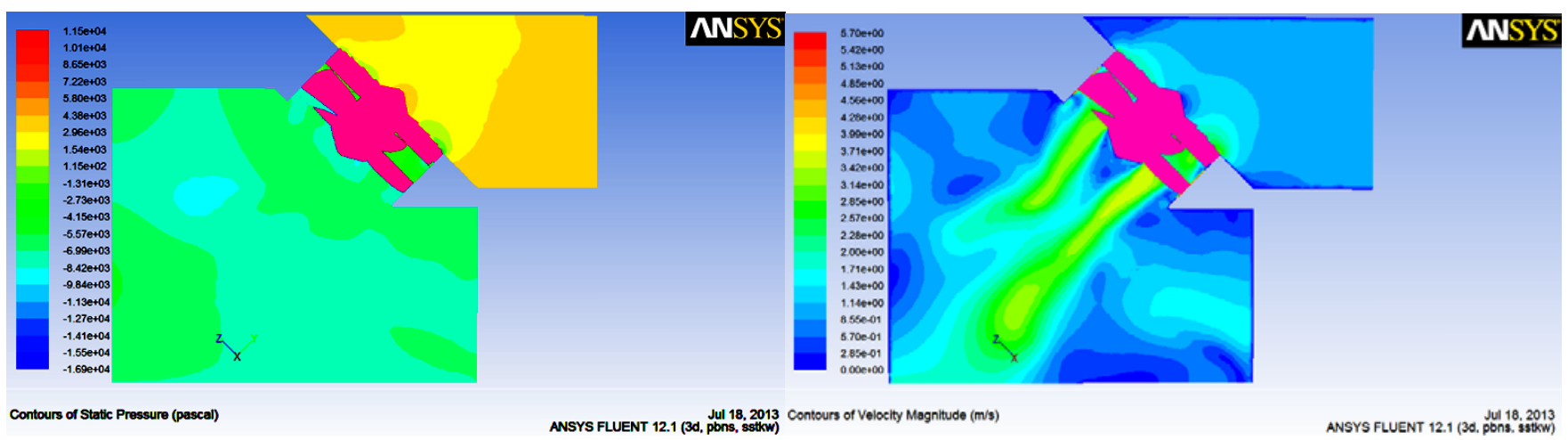

Fig. 13 Static pressure distribution (left) and velocity distribution (right) along y-axis3

\subsection{Forced Vortex Result}

Simulations on these criteria generally showed are identical with free vortex results for the velocities and pressures distribution that occurs on turbine installation and turbine blades (fig.17). The velocities distribution at the outlet area of the runner blade are shown higher and static pressures on the same area are also has a lower level. Figure 18 shows the minimum and maximum static 
pressure of turbine blade on the suction side and on the trailing edge. Minimum and maximum static pressure are $-19.096 \mathrm{kPa}$ and $11.264 \mathrm{kPa}$ respectively. For the designed turbine operation, mass flow rate $549 \mathrm{~kg} / \mathrm{s}$ and rotation $180 \mathrm{rpm}, 85.17 \%$ efficiency obtained with a total of $2,464 \mathrm{~kW}$ power. And the maximum efficiency obtained for the same mass flow rate is $91.25 \%$ at $150 \mathrm{rpm}$ rotation, this generating a total power $2.603 \mathrm{~kW}$ (fig. $15 \& 16$ ).

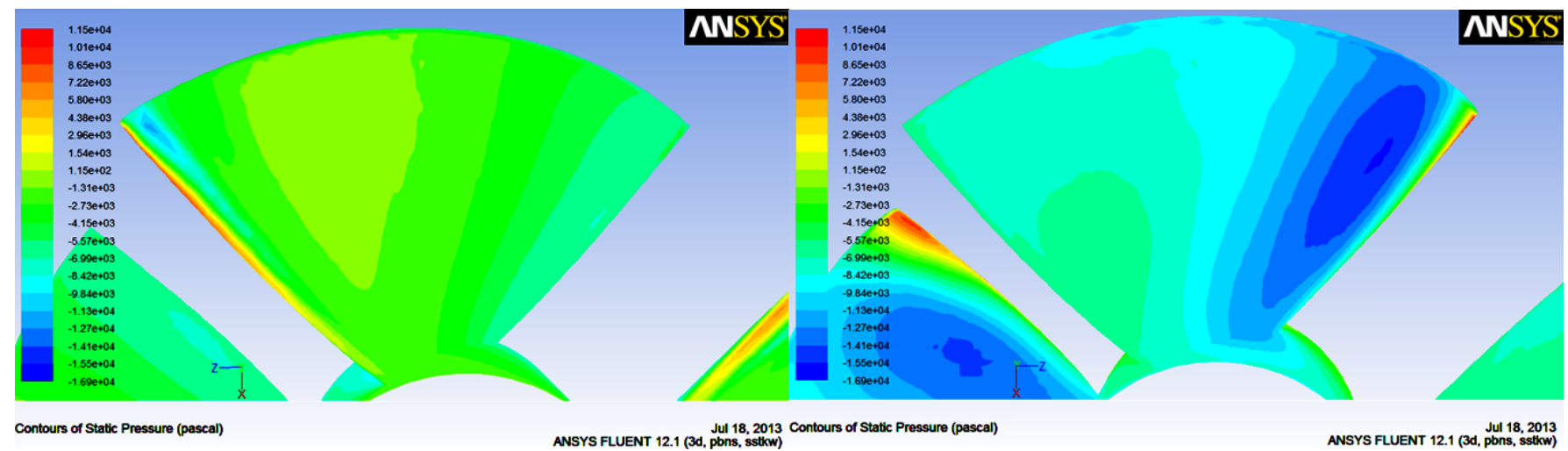

Fig. 14 Static pressure distribution on runner blade for pressure side (left) and suction side (right)
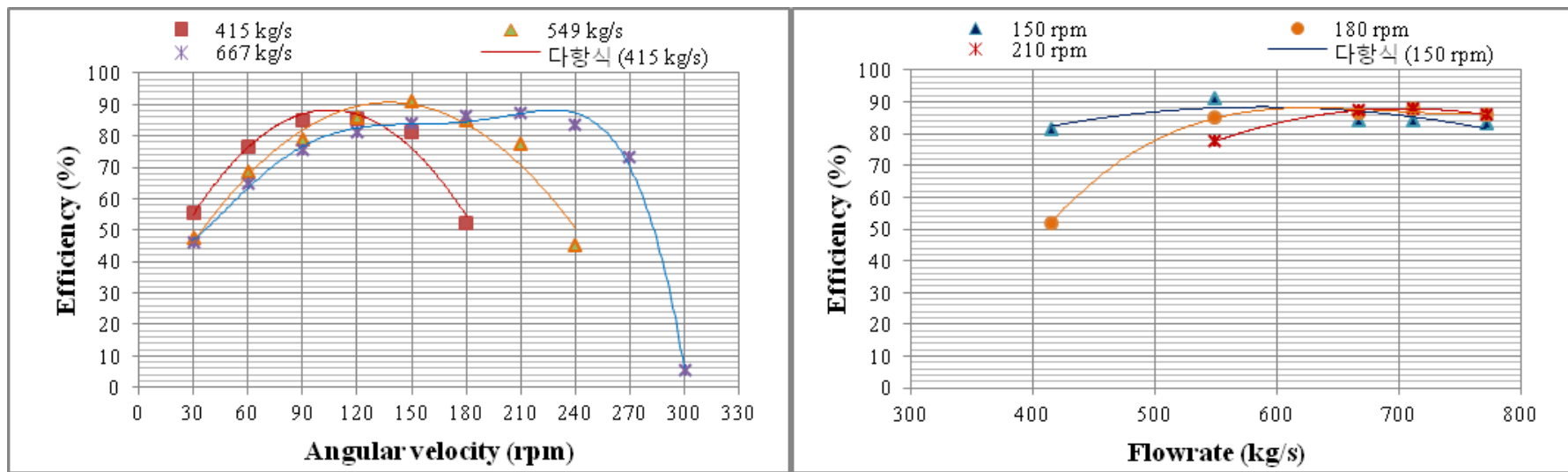

Fig. 15 Efficiency results at various of angular velocity and flow rate

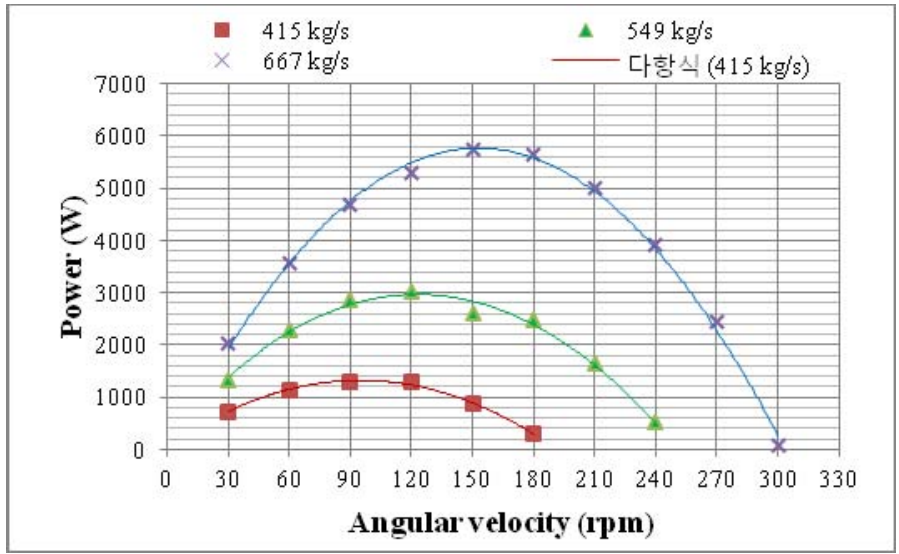

Fig. 16 Power results at various of angular velocity

\subsection{Swirl Velocity Constant Result}

Simulation results on fig. 19 and 20 shows the maximum efficiency of the turbine operating at design mass flow rate $549 \mathrm{~kg} / \mathrm{s}$ and rotation $180 \mathrm{rpm}$ is $88.12 \%$ which produce $2,227 \mathrm{~kW}$ of power. Maximum efficiency obtained in this operating condition is $89.47 \%$ at $150 \mathrm{rpm}$ rotation with $2.731 \mathrm{~kW}$ power. Figure 21 shows the velocity and static pressure distribution, this indicates the velocity of water increased over the turbine blade outlet and also shows the static pressure drop in the same area. The turbine blade static pressure on the pressure side is higher than the suction side, a minimum static pressure located on suction side close to the leading edge and the maximum one occurs at the leading edge. Minimum and maximum static pressure obtained $-28.434 \mathrm{kPa}$ 
and $5.335 \mathrm{kPa}$ respectively.

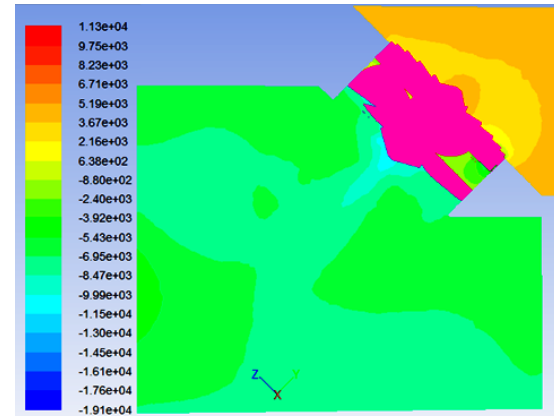

MSYS

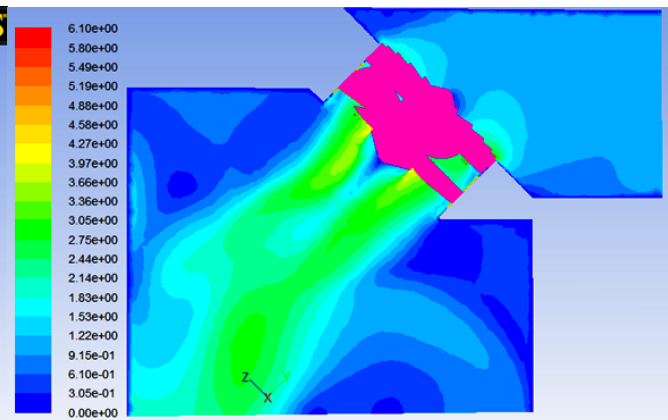

MNSYS

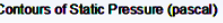

ANSYS FLUENT 12.1 (3d, pbbss, ssthw)

Fig. 17 Static pressure distribution (left) and velocity distribution (right) along y-axis

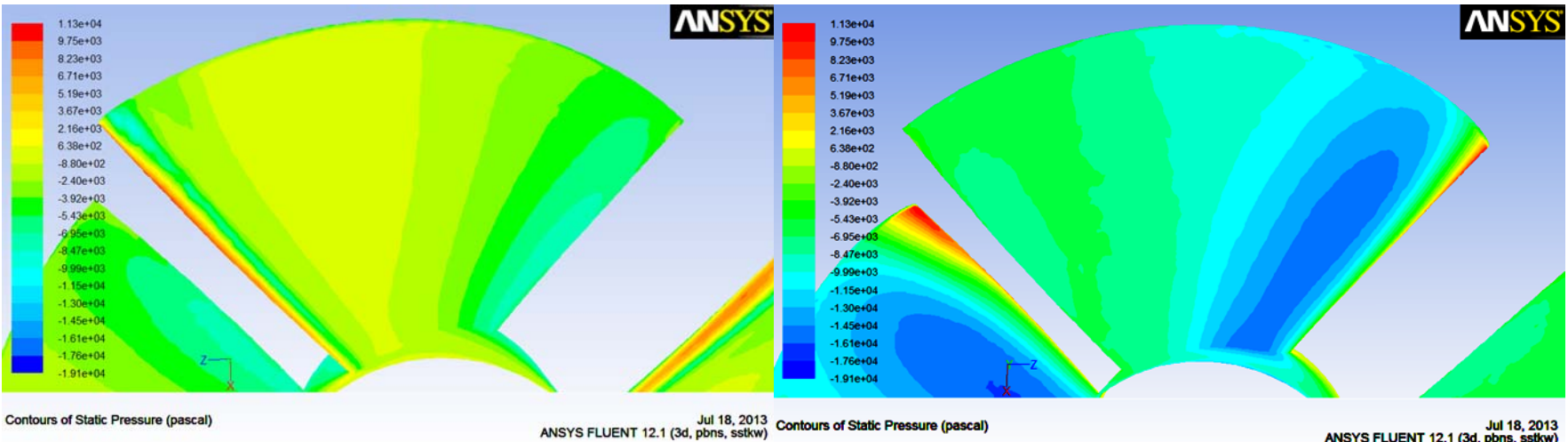

Fig. 18 Static pressure distribution on runner blade for pressure side (left) and suction side (right)
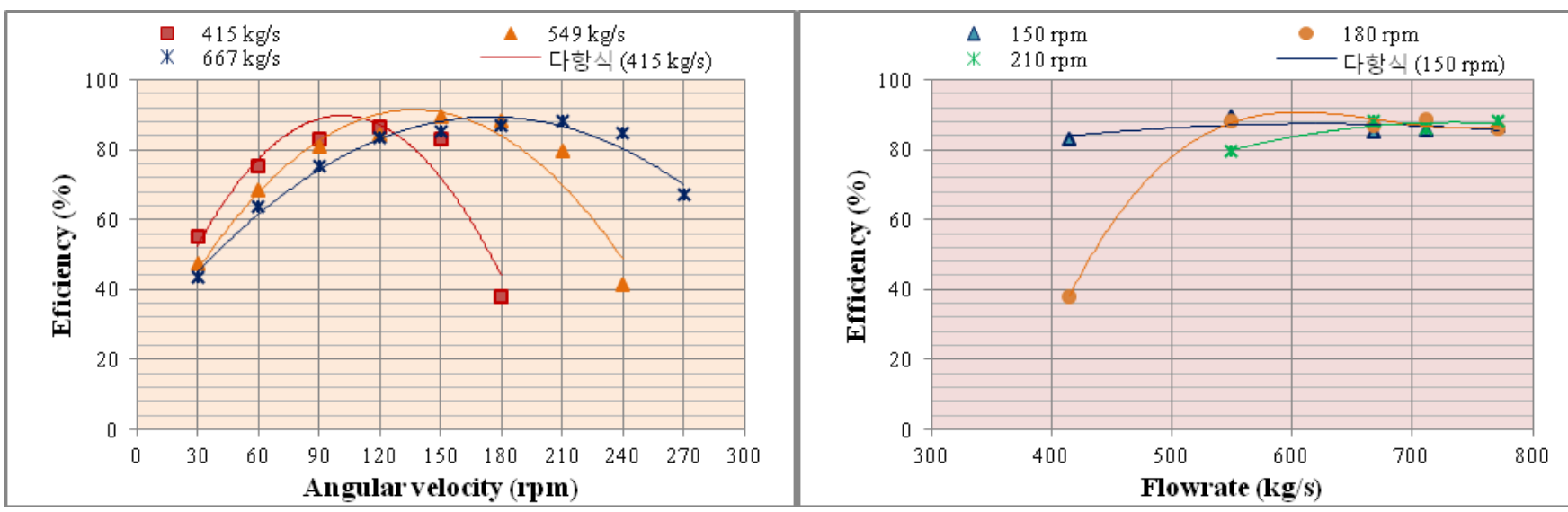

Fig. 19 Efficiency results at various of angular velocity and flow rate

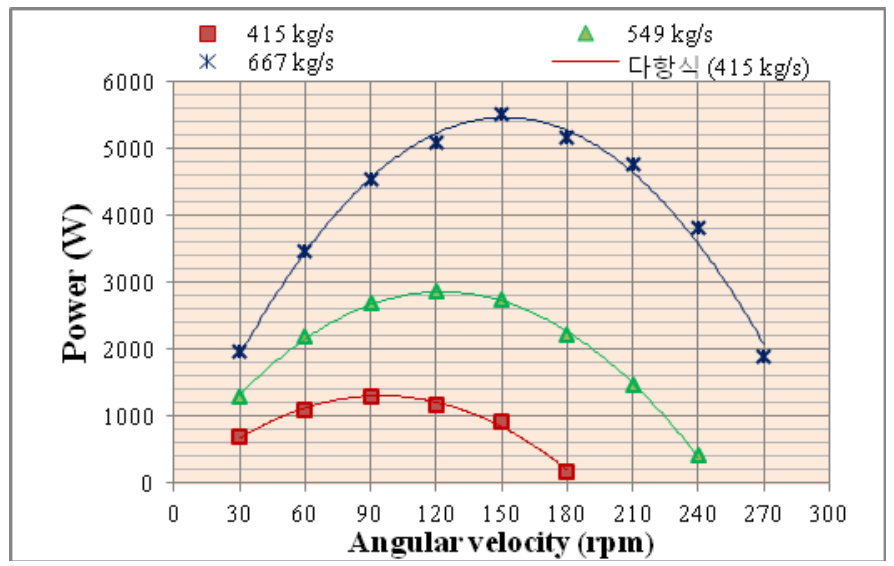

Fig. 20 Power results at various of angular velocity 


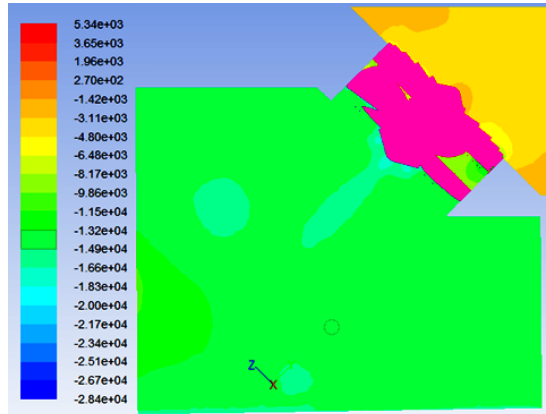

Contours of Static Pressure (pascal)
MNSY

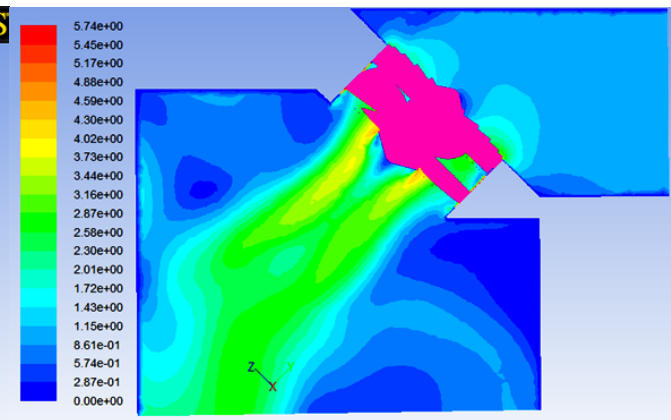

ANSYS FLUENT 121 (3d, pbils, 18,2013 , ssthw)

Fig. 21 Static pressure distribution (left) and velocity distribution (right) along y-axis

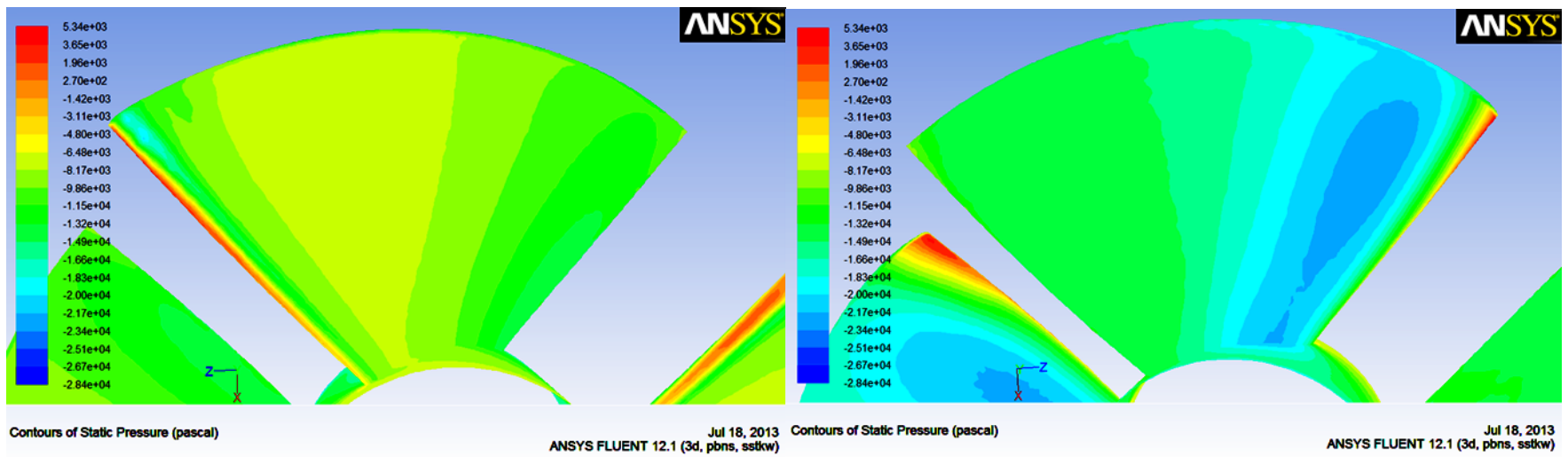

Fig. 22 Static pressure distribution on runner blade for pressure side (left) and suction side (right)

\section{Conclusion}

We can obtained the comparisons of the velocity and static pressure distribution between these criterions as shown in table 2 , which indicates the opportunity for the occurrence of cavitation in the turbine installation. Figure 23 shows a comparison of the power generated by the turbine at designed operating range $(549 \mathrm{~kg} / \mathrm{s}$ and $180 \mathrm{rpm})$ with a variation of the angular velocity and mass flow rate, and the non-free vortex generating higher power than free vortex criterion. The forced vortex criterion produces an average power $15 \%$ higher and swirl velocity constant criterion produces an average power $9 \%$ higher than free vortex criterion. The resulting power difference is due to the differences in pressure drop generated by turbine at the same mass flow rate operation. But on fig. 24, the turbine efficiency for all criterions are not significantly different.

Table 2 Comparisons of distribution of velocity and pressure static minimum \& maximum

\begin{tabular}{l||c||c||c}
\hline \multicolumn{1}{c|}{ Turbine criterion } & Max Velocity distr. (m/s) & Min. Pressure distr. (kPa) & Max. Pressure distr. (kPa) \\
\hline Free vortex & 5.70 & -16.947 & 11.490 \\
\hline Forced vortex & 6.10 & -19.096 & 11.264 \\
\hline S. V. constant & 5.74 & -28.434 & 5.335 \\
\hline
\end{tabular}

From the comparison of the three turbines that was designed with a different velocity swirl criterion then on-free vortex is superior in generating power. However, the pressure distributions in these turbines are also lower than free vortex criterion, so we need to consider carefully the possibility of cavitation occurs in the turbine. 


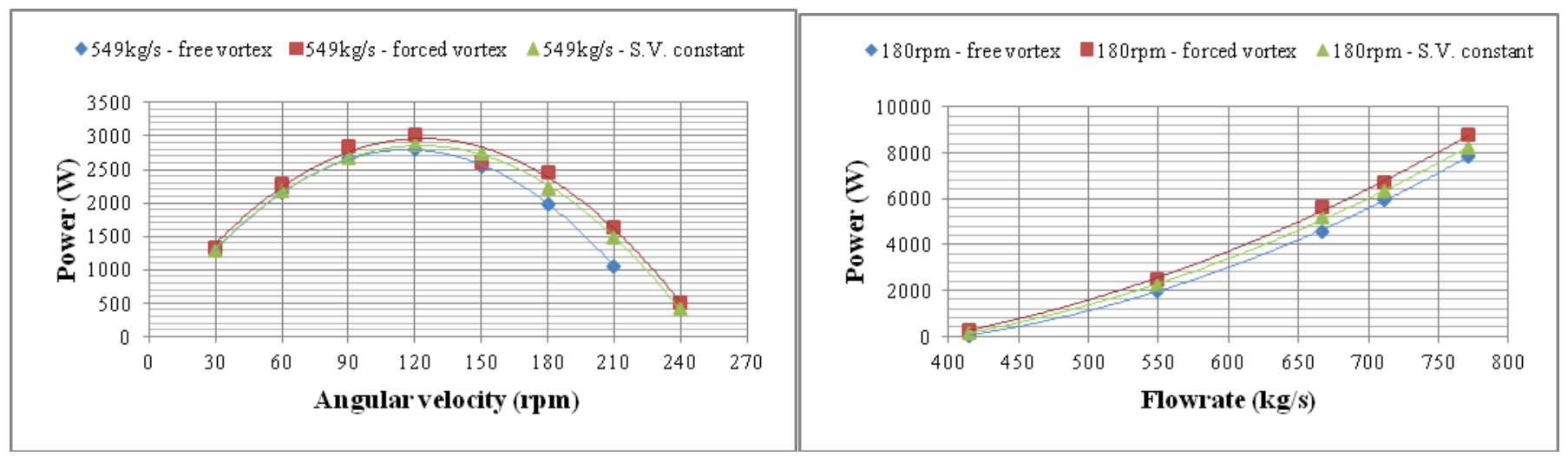

Fig. 23 Comparison of the power results at various of angular velocity and flow rate

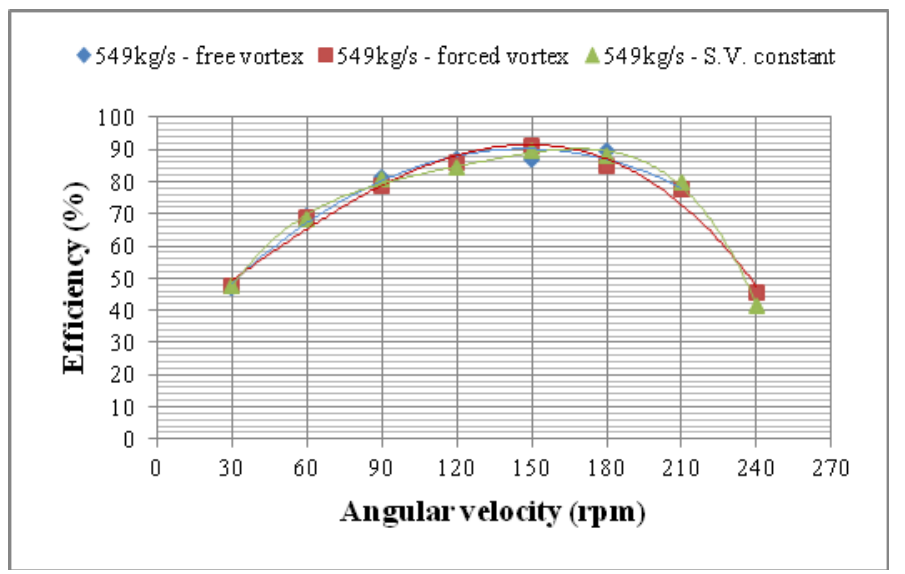

Fig. 24 Comparison of the efficiency results at various of angular velocity

\section{Acknowledgments}

The author would like to express special thanks to BPPS DIKTI for financial support and ITB for a chance to study and research.

\section{Nomenclature}

Fluid density $\left[\mathrm{kg} / \mathrm{m}^{3}\right]$

Gravity acceleration $\left[\mathrm{kg} / \mathrm{s}^{2}\right]$

Water flow rate $\left[\mathrm{m}^{3} / \mathrm{s}\right]$

Head[m]

Meridional velocity $[\mathrm{m} / \mathrm{s}]$

Swirl velocity $[\mathrm{m} / \mathrm{s}]$

$\begin{array}{ll}C_{L} & \text { Lift coefficient } \\ C_{D} & \text { Drag coefficient } \\ L & \text { Lift force [N] } \\ D & \text { Drag force [N] } \\ P_{W} & \text { Power of water [W] } \\ P_{T} & \text { Power of turbine [W] }\end{array}$

\section{References}

[1] Priyono Sutikno and Ibrahim Khalil Adam, 2011, Institut Teknologi Bandung, "Design, Simulation and Eperimental of the Very Low Head Turbine with Minimum Pressure and Free Vortex Criterions," International Journal of Mechanical \& Mechatronics, International Journal of Engineering \& Science, IJMME-IJENS Vol. 11 No. 1, ISSN 2077-124X.

[2] Priyono Sutikno and I Nengah Diasta, 2011, Quasi 3D Inverse Design Method, "Optimization Criterion for Very Low Head Axial Turbine Design," FTEC2011-The 7th International Conference on Fluid and Thermal Energy Conversion, Zhengzhou, China, September 24-27, 2011.

[3] International Energy Agency, 2012, World Energy Outlook 2012,www.iea.org.

[4] BPPT, 2012, Outlook Energy Indonesia 2012,www.bppt.go.id.

[5] Lewis, R. I., 1996, “Turbomachinery Performance Analysis," Elsevier Science and Technology Books.

[6] Furukawa, A, "Research\& Development of Darrieus type Hydro Turbine for Extra-Low-Head Hydro Power Utilization," Kyushu University.

[7] Mamun, M., 2006, "The Study on the Hysteretic Characteristics of the Wells Turbine in a Deep Stall Condition," Ph. D. Thesis, Department of Energy and Material Science Graduate School of Science and Engineering, Saga University, Japan.

[8] O’Neil, C., Leclerc, M., Deschene, C., 2008, “A New Turbine for Very Low Head Application,” www.vlh-turbine.com. 